\title{
Gambaran Kejadian Retinopati Hipertensi pada Penderita Hipertensi yang Dirawat di Bagian Penyakit Dalam RSUP dr. M. Djamil pada Bulan Januari-Desember 2013
}

Seilla Dinta Yastina ${ }^{1}$, Rudy Afriant ${ }^{2}$, Yenita $^{3}$

\begin{abstract}
Abstrak
Hipertensi bisa mengakibatkan kerusakan pada target organ seperti jantung, ginjal, otak, dan mata. Kerusakan target organ dapat dideteksi dengan melihat gambaran retinopati hipertensi. Pada retinopati hipertensi stadium III dan IV pada klasifikasi Keith-Wagener-Barker akan terjadi kerusakan target organ lain dan penurunan visus serta kebutaan. Tujuan penelitian ini adalah untuk mengetahui gambaran kejadian retinopati hipertensi pada penderita hipertensi yang di rawat di Bagian Penyakit Dalam RSUP Dr. M. Djamil. Penelitian ini bersifat deskriptif dengan menggunakan data rekam medik pasien dengan diagnosis hipertensi dari Januari sampai Desember 2013. Seluruh anggota populasi dijadikan sampel sesuai kriteria inklusi dan eksklusi, sehingga diperoleh sampel sebanyak 144 orang. Hasil penelitian yang didapatkan yaitu $46.5 \%$ dari penderita hipertensi mendapat retinopati hipertensi. Pada pasien dengan retinopati hipertensi, $65.7 \%$ dengan TDS $>160 \mathrm{mmHg}$ dan/atau TDD $>100 \mathrm{mmHg}, 55.2 \%$ menderita hipertensi $>5$ tahun, 95.5\% merupakan kelompok usia > 40 tahun, 62.7\% adalah perempuan, dan $62.7 \%$ dengan Keith-Wagerner-Barker II. Berdasarkan hasil penelitian ini disimpulkan bahwa sebagian besar pasien retinopati hipertensi dengan Keith-Wagerner-Barker II pada pasien dengan TDS $>160 \mathrm{mmHg}$ dan/atau TDD $>100 \mathrm{mmHg}$, menderita hipertensi $>5$ tahun, dengan umur $>40$ tahun.
\end{abstract}

Kata kunci: gambaran, hipertensi, retinopati hipertensi

\begin{abstract}
Hypertension can make target organ damage, such as heart, kidney, brain and eye. Detect the target organ demage can see by hypertensive retinopathy in the eye. In the hypertensive retinopathy grade II and IV in Keith-WagenerBarker's classification will happen target organ damage and blind. The objective of the study was to know the incident of hypertensive retinopathy in hypertensive patients in internal medicine department of RSUP DR. M. Djamil. This research was a descriptive study using medical records of hypertensive patient from January until December 2013. The 144 samples were all of populations who are appropriate with inclusion and exclusion criterias. The result of the study found that $46.5 \%$ hypertensive patients get retinopathy. In hypertensive retinopathy patients, there is $65.7 \%$ with $S B P>160 \mathrm{mmHg}$ and/or DBP >100 $\mathrm{mmHg}, 55.2 \%$ gotten hypertension since $>5$ years ago, $95.5 \%$ is in the age group $>40$ years, $62.7 \%$ is female, and $62.7 \%$ is with Keith-Wagener-Barker II. Based on the results of this study, it can be concluded that incidence of hypertensive retinopathy was in Keith-Wagener-Barker II, in patient who had gotten hypertension $>5$ years ago, and in the $>40$ years.
\end{abstract}

Keywords: overview, hypertension, hypertensive retinopathy

Affiliasi penulis: 1. Prodi Profesi Dokter FK Unand (Fakultas Kedokteran Universitas Andalas Padang), 2. Bagian IImu Penyakit Dalam FK Unand/RSUP Dr. M. Djamil Padang, 3. Bagian Patologi Anatomi FK Unand.
Korespondensi: Seilla Dinta Yastina Email :

Seilla_dint@yahoo.co.id Telp: 085374776988 


\section{PENDAHULUAN}

Hipertensi merupakan manifestasi gangguan keseimbangan hemodinamik sistem kardiovaskular. Sampai saat ini, hipertensi masih menjadi salah satumasalah kesehatan di dunia karena terjadi tanpa tanda dan gejala, sehingga penderita tidak mengetahui bahwa dirinya terkena hipertensi. Dari survey yang dilakukan oleh JNC 7 di Amerika Serikat pada tahun 1999-2000, 70\% penderita hipertensi mengetahui bahwa mereka menderita hipertensi. Dari $70 \%$ tersebut, hanya $59 \%$ yang mencari pertolongan medis. Dari $59 \%$ tersebut, hanya $34 \%$ yang bisa mengontrol tekanan darahnya. ${ }^{1}$ Laporan Statistik Kesehatan Dunia 2012 menyebutkan bahwa satu dari tiga orang dewasa di seluruh dunia menderita hipertensi. Komplikasi dari hipertensi, seperti stroke dan penyakit jantung bisa menyebabkan kematian. Prevalensi hipertensi diperkirakan akan terus meningkat, dan diprediksi pada tahun 2025 sebanyak $29 \%$ orang dewasa di seluruh dunia menderita hipertensi, sedangkan di Indonesia diperkirakan angkanya mencapai $31,7 \%{ }^{2}$

Data Riset Kesehatan Dasar tahun 2013, didapatkan prevalensi hipertensi di Indonesia adalah $25,8 \%$. Terjadi peningkatan prevalensi hipertensi berdasarkan wawancara (apakah pernah didiagnosis oleh tenaga kesehatan dan minum obat hipertensi) dari 7,6 \% tahun 2007 menjadi 9,5\% pada tahun 2013. ${ }^{3}$ Profil Kesehatan Kota Padang menunjukkan hipertensi termasuk dalam urutan ke 8 penyakit terbanyak pada tahun $2012{ }^{4}$

Hipertensi dapat menimbulkan kerusakan pada organ tubuh, baik secara langsung maupun tidak langsung. Kerusakan target organ yang umum ditemukan pada pasien hipertensi adalah jantung (hipertrofi ventrikel kiri, angina atau infark miokardium, gagal jantung), otak (strok, demensia), penyakit ginjal kronik, penyakit arteri perifer, dan retinopati. ${ }^{5}$ Kerusakan pada target organ akan terlihat setelah menderita hipertensi bertahun-tahun, karena hipertensi tidak menampakkan gejala yang jelas sebelum mengenai target organ. Namun, kesadaran terkait hipertensi, pengobatan, dan kontrol masih kurang optimal. Oleh karena itu, strategi untuk mendeteksi hipertensi sebelum terjadinya gejala kerusakan organ lain sangat penting. Deteksi tersebut bisa dilihat dari retina. ${ }^{6}$

Retinopati hipertensi menunjukkan perubahan mikrovaskuler retina dalam merespon peningkatan tekanan darah. ${ }^{7}$ Pada awalnya, retinopati hipertensi juga tidak memperlihatkan gejala yang jelas. Namun ketika sudah mencapai stadium III atau stadium IV pada klasifikasi Keith-Wagener-Barker, akan terjadi kerusakan target organ lainnya dan disertai penurunan visus atau penglihatan kabur. ${ }^{6}$ Retinopati hipertensi bisa menimbulkan komplikasi berupa oklusi cabang vena retina (BRVO) atau oklusi arteri retina (CRAO) yang menyebabkan kehilangan penglihatan secara tiba-tiba. ${ }^{8}$

Penelitian yang dilakukan Beaver Dam Eye Study, 50\%-70\% penderita hipertensi mengalami perdarahan retina dan mikroaneurisma, 30\%-40\% penyempitan arteri fokal, dan $70 \%-80 \%$ mengalami Arterivenous (AV) nicking dibandingkan orang dengan normotensi. ${ }^{9}$ Kejadian retinopati hipertensi pada orang dewasa biasanya timbul pada usia 40 tahun atau lebih. ${ }^{7}$ Pada penelitian Tien $Y$ Wong dan Paul Mitchell pada tahun 2004, prevalensi retinopati hipertensi berdasarkan klasifikasi Keith-WagenerBarker berkisar antara 2\%-15\%. Penelitian itu menunjukkan bahwa berkisar $6 \%-10 \%$ timbulnya berbagai tanda-tanda retinopati setelah lima sampai tujuh tahun menderita hipertensi. ${ }^{10}$ Penelitian di Afrika pada tahun 2012 , sekitar $78 \%$ pasien hipertensi menderita retinopati hipertensi berdasarkan klasifikasi Keith-Wagener-Barker grade 1 dan 2, dan 2,2\% dengan retinopati grade 3 dan 4 . Retinopati grade 3 dan 4 digunakan sebagai bukti kerusakan target organ. ${ }^{11}$ Hasil penelitian lain yang dilakukan di RS dr. Kariadi Semarang, distribusi kejadian retinopati hipertensi berdasarkan klasifikasi Keith-WagenerBarker pada penderita hipertensi non diabetik sebanyak $87,5 \%{ }^{12}$

Kejadian hipertensi semakin meningkat dan tidak menampakkan gejala secara jelas sebelum terjadinya kerusakan target organ. Biasanya penyakit target organ yang paling awal adalah retinopati hipertensi, sehingga retinopati hipertensi bisa menjadi indikator terjadinya kerusakan target organ lain. Pada retinopati hipertensi yang sudah berat, dapat 
menyebabkan kaburnya penglihatan bahkan kebutaan

oleh karena itu, perlu dilakukan penelitian tentang gambaran kejadian retinopati hipertensi pada penderita hipertensi yang dirawat di Bagian Penyakit Dalam RSUP dr. M. Djamil pada bulan Januari Desember 2013

\section{METODE}

Penelitian ini bersifat deskriptif dengan menggunakan desain retrospektif untuk mengetahui gambaran gambaran kejadian retinopati hipertensi pada penderita hipertensi yang dirawat di bagian Penyakit Dalam RSUP Dr. M. Djamil Pada bulan Januari-Desember 2013.

HASIL

Tabel 1. Distribusi frekuensi penderita hipertensi

\begin{tabular}{ccc}
\hline Retinopati Hipertensi & $\mathbf{n}$ & \% \\
\hline+ & 67 & 46.5 \\
- & 77 & 53.5 \\
\hline Jumlah & 144 & 100
\end{tabular}

Pada Tabel 1 terlihat bahwa dari 144 data penderita hipertensi didapatkan pasien retinopati hipertensi sebanyak 67 orang (46.5\%).

Tabel 2. Distribusi frekuensi retinopati hipertensi berdasarkan tekanan darah

\begin{tabular}{|c|c|c|c|}
\hline \multicolumn{2}{|c|}{ Tekanan Darah (mmHg) } & \multirow[t]{2}{*}{$n$} & \multirow[t]{2}{*}{$\%$} \\
\hline Sistolik & Diastolik & & \\
\hline$<120$ & dan $<80$ & 1 & 1.5 \\
\hline $120-139$ & dan/atau 80-89 & 2 & 3.0 \\
\hline 140-159 & dan/atau 90-99 & 20 & 29.9 \\
\hline \multirow[t]{2}{*}{$\geq 160$} & dan/atau $\geq 100$ & 44 & 65.7 \\
\hline & llah & 67 & 100 \\
\hline
\end{tabular}

Pada Tabel 2 dilihat bahwa dari 67 data penderita retinopati hipertensi didapatkan klasifikasi tekanan darah terbanyak adalah sistolik $\geq 160 \mathrm{mmHg}$ dan/atau diastolik $\geq 100 \mathrm{mmHg}$ sebanyak 44 orang (65.7\%).
Tabel 3. Distribusi frekuensi retinopati hipertensi berdasarkan lama menderita hipertensi

\begin{tabular}{ccc}
\hline $\begin{array}{c}\text { Lama Hipertensi } \\
\text { (th) }\end{array}$ & $\mathbf{n}$ & $\%$ \\
\hline$<5$ & 30 & 44.8 \\
$\geq 5$ & 37 & 55.2 \\
\hline Jumlah & 67 & 100 \\
\hline
\end{tabular}

Pada Tabel 3 dilihat bahwa dari 67 data penderita retinopati hipertensi didapatkan riwayat menderita hipertensi terbanyak adalah $\geq 5$ tahun, sebanyak 37 orang (55.6\%).

Tabel 4. Distribusi frekuensi retinopati hipertensi berdasarkan umur

\begin{tabular}{ccc}
\hline Umur (th) & $\mathbf{n}$ & $\%$ \\
\hline$<40$ & 3 & 4.5 \\
$\geq 40$ & 64 & 95.5 \\
\hline Jumlah & 67 & 100.0 \\
\hline
\end{tabular}

Pada Tabel 4 dilihat bahwa dari 67 data penderita retinopati hipertensi didapatkan kelompok umur terbanyak adalah $\geq 40$ tahun yaitu sebanyak 64 orang (95.5\%).

Tabel 5. Distribusi frekuensi retinopati hipertensi berdasarkan jenis kelamin

\begin{tabular}{ccc}
\hline Jenis Kelamin & $\mathbf{n}$ & \% \\
\hline Laki-laki & 25 & 37.3 \\
Perempuan & 42 & 62.7 \\
\hline Jumlah & 67 & 100 \\
\hline
\end{tabular}

Pada Tabel 5 dilihat bahwa dari 67 data penderita retinopati hipertensi didapatkan jenis kelamin terbanyak adalah perempuan sebanyak 42 orang $(62.7 \%)$.

Tabel 6. Distribusi frekuensi retinopati hipertensi berdasarkan grade retinopati hipertensi

\begin{tabular}{ccc}
\hline Retinopati hipertensi & $\mathbf{n}$ & $\%$ \\
\hline KW stadium I & 17 & 25.4 \\
KW stadium II & 42 & 62.7 \\
KW stadium III & 7 & 10.4 \\
KW stadium IV & 1 & 1.5 \\
\hline Jumlah & 67 & 100 \\
\hline
\end{tabular}


Pada Tabel 6 dilihat bahwa dari 67 data

retinopati hipertensi terbanyak adalah KW II penderita retinopati hipertensi didapatkan grade sebanyak 42 orang $(62.7 \%)$.

Tabel 7. Distribusi frekuensi faktor-faktor yang berhubungan dengan derajat Retinopati Hipertensi

\begin{tabular}{|c|c|c|c|c|c|c|}
\hline \multicolumn{3}{|c|}{$\begin{array}{c}\text { Retinopati hipertensi } \\
\text { Derajat Hipertensi (mmHg) }\end{array}$} & \multirow[t]{2}{*}{ KW I } & \multirow[t]{2}{*}{ KW II } & \multirow[t]{2}{*}{ KW III } & \multirow[t]{2}{*}{ KW IV } \\
\hline sistolik & & diastolik & & & & \\
\hline$<120$ & Dan & $<80$ & 1.49 & - & - & - \\
\hline $120-139$ & dan/atau & $80-89$ & 2.98 & - & - & - \\
\hline $140-159$ & dan/atau & $90-99$ & 11.9 & 14.9 & 2.98 & - \\
\hline$\geq 160$ & dan/atau & $\geq 100$ & 8.95 & 46.2 & 8.95 & 1.49 \\
\hline \multicolumn{7}{|c|}{ Lama Hipertensi (th) } \\
\hline & $<5$ & & 14.9 & 23.8 & 5.97 & - \\
\hline & $\geq 5$ & & 10.4 & 38.8 & 4.47 & 1.49 \\
\hline \multicolumn{7}{|c|}{ Umur (th) } \\
\hline & $<40$ & & 1.49 & 1.49 & 1.49 & - \\
\hline & $\geq 40$ & & 23.8 & 61.1 & 8.95 & 1.49 \\
\hline
\end{tabular}

Pada Tabel 7 dilihat bahwa dari 67 data penderita retinopati hipertensi didapatkan grade retinopati hipertensi terbanyak adalah KW II, yaitu sebanyak 31 (46.2\%) orang pada pasien dengan TDS $\geq 160$ dan/atau TDD $\geq 100,26$ (38.8\%) pasien pada pasien yang menderita hipertensi $\geq 5$ tahun, dan 41 $(61.1 \%)$ pasien dengan umur $\geq 40$ tahun.

\section{PEMBAHASAN}

Hasil penelitian ini terdapat 538 data rekam medik penderita hipertensi di Penyakit Dalam RSUP dr. M.Djamil pada bulan Januari-Desember 2013. Dari data tersebut, didapatkan 144 data penderita hipertensi yang memenuhi kriteria inklusi dan eksklusi. Dari data yang memenuhi kriteria ekslusi dan inklusi, ditemukan 67 pasien hipertensi yang mengalami retinopati hipertensi.

Persentase penderita retinopati hipertensi pada pasien hipertensi di Penyakit Dalam RSUP dr. M.Djamil adalah $46.5 \%$. Kelainan mikrovaskular retina, seperti penyempitan umum dan fokal pada arteriol, AV-nicking, mencerminkan kerusakan vaskular yang disebabkan oleh peningkatan tekanan darah, penuaan, dan proses lainnya. Studi epidemiologi yang dilakukan Wong et al menunjukkan bahwa ditemukan retinopati hipertensi pada 2-15\% populasi masyarakat umum nondiabetes, dan ini sangat berkaitan erat dengan tekanan darah yang tinggi. ${ }^{13}$ Pada penelitian The Multi-Ethnic Study of
Atherosclerosis (MESA), prevalensi retinopati di US adalah $5.8 \%$ untuk masyarakat tanpa diabetes atau hipertensi, 9.6\% untuk masyarakat hanya dengan hipertensi saja, dan $24.3 \%$ jika memiliki hipertensi dan diabetes. ${ }^{14}$ Besharati et al meneliti dari 213 pasien hipertensi, 85 pasien (39.9\%) yang menderita retinopati hipertensi dilihat dengan menggunakan optalmoskop lansung. ${ }^{15}$

Penelitian ini berbeda dengan penelitian Setyowati (2005). Persentase retinopati hipertensi di RSUP Kariadi sangat tinggi, yaitu $87.5 \% .{ }^{12}$ Hal ini disebabkan karena semua pasien hipertensi pada penelitian Setyowati dikonsul ke bagian mata, sedangkan pada penelitian ini tidak semua pasien hipertensi yang dikonsul ke bagian mata.

Berdasarkan Tabel 2, didapatkan klasifikasi derajat tekanan darah terbanyak pada penderita retinopati hipertensi adalah TDS $\geq 160 \mathrm{mmHg}$ dan/atau TDD $\geq 100 \mathrm{mmHg}$ (hipertensi derajat II) sebanyak 44 orang (65.7\%). Penelitian ini sejalan dengan penelitian Kabedi et al yang menyatakan bahwa retinopati hipertensi lebih banyak ditemukan pada pasien dengan hipertensi derajat II yaitu sebanyak $69.8 \%$, dan $30.2 \%$ dengan hipertensi derajat I. ${ }^{16}$ Insiden retinopati lebih tinggi pada pasien yang tekanan darahnya meningkat daripada pasien dengan tekanan darah normal atau terkontrol. ${ }^{17}$

Pada penelitian ini, sebanyak 37 orang (55.6 $\%$ ) pasien mendapat retinopati hipertensi setelah $\geq 5$ 
tahun menderita hipertensi. Sesuai dengan literatur yang menjelaskan bahwa terlihatnya penyempitan arteri retina secara umum dan $A V$ nicking menjadi penanda hipertensi yang kronis. Perubahan itu secara langsung berkaitan dengan peningkatan tekanan darah yang diukur 5-8 tahun sebelumnya. ${ }^{9}$ Foto retina yang dilakukan pada penelitian ke-3 Artherosclerosis Risk in Communities (ARIC) pada tahun 1993-1995 terhadap 9.300 partisipan yang tidak menderita diabetes, dan berumur 50-71 tahun didapatkan bahwa penyempitan arteriol berhubungan erat dengan peningkatan tekanan darah pada pasien yang mendapatkan obat antihipertensi ataupun tidak. Diperkirakan, perubahan retina juga berkaitan dengan peningkatan tekanan darah 3-6 tahun sebelum dilakukan pemeriksaan retina. ${ }^{18}$ Pada penelitian ini tidak tergambar perbedaan yang signifikan terkait lamanya riwayat hipertensi pada pasien dengan retinopati hipertensi, karena hanya beberapa pasien yang dikonsulkan ke bagian mata, dan beberapa pasien baru mengetahui menderita hipertensi, menyangkal hipertensi, atau hanya menduga-duga riwayat hipertensinya.

Pada penelitian ini, sebanyak 64 orang $(95.5 \%)$ pasien retinopati hipertensi berusia $\geq 40$ tahun. Menurut literatur, tanda-tanda retinopati hipertensi umumnya muncul pada orang berusia 40 tahun atau lebih. ${ }^{19} \mathrm{Di}$ dalam penelitiannya, Kabedi et al menyatakan bahwa resiko retinopati hipertensi akan meningkat pada orang yang berusia $>50$ tahun dan perokok. ${ }^{16}$ Pada penelitian Besharati et al, retinopati hipertensi terbanyak terdapat pada usia 25-59 tahun (45.8\%), >70 tahun (40.3\%), 65-69 tahun (38.6\%), dan 60-64 tahun (32.6\%). Namun menurut Besharati et al, tidak ada hubungan yang sangat significan antara usia dan kejadian retinopati hipertensi. $^{15}$

Tanda-tanda retinopati seperti mikroaneurisma, perdarahan retina, cotton-wool spots, dapat ditemukan pada orang tua. Penelitian memperlihatkan lebih dari $10 \%$ orang berusia 40 tahun atau lebih terdeteksi retinopati. ${ }^{7}$ Pada penelitian ini sangat terlihat perbedaan frekuensi retinopati hipertensi berdasarkan umur pasien. Ini disebabkan karena kejadian hipertensi juga meningkat seiring meningkatnya usia.
Pasien berjenis kelamin perempuan lebih banyak mendapat retinopati hipertensi dibandingkan laki-laki, yaitu sebanyak 42 orang $(62.7 \%)$. Menurut penelitian Besharati et al, perbandingan jenis kelamin penderita retinopati hipertensi antara laki-laki dan perempuan adalah $32.6 \%: 42.8 \%$. Jadi, prevalensi kejadian retinopati pada perempuan 1.4 kali lebih besar dibandingkan laki-laki. ${ }^{15}$ Pada penelitian ini perempuan lebih banyak menderita retinopati hipertensi karena rata-rata pasien yang menderita hipertensi di Penyakit Dalam juga berjenis kelamin perempuan. Sebagaimana digambarkan pada penelitian Sedayu di RSUP dr. M.Djamil pada tahun 2013,64.3\%. pasien hipertensi yang dirawat inap di bangsal Penyakit Dalam adalah perempuan. ${ }^{20}$ Begitu pun pada penelitian Hamidi, perempuan lebih banyak dirawat di Penyakit Dalam RSUP dr. M.Djamil pada tahun 2010 dengan diagnosis hipertensi esensial. Distribusinya adalah $58.13 \%{ }^{21}$

Derajat retinopati hipertensi terbanyak berdasarkan klasifikasi Keith-Wagerner-Barker adalah KW II, yaitu 42 pasien (62.7\%). Hal ini sejalan dengan distribusi retinopati hipertensi berdasarkan derajatnya menurut klasifikasi Keith-Wagerner-Barker pada penelitian Neto et al (2010), disajikan sebagai berikut : KW I ditemukan pada 42 pasien (42,4\%), KW II ditemukan pada 52 pasien $(52,6 \%)$, KW III ditemukan pada 3 pasien (3\%) dan KW IV tidak ada. Gambaran ini didapatkan dengan menggunakan angiography. ${ }^{22}$ Pada penelitian Cuspidi et al, distribusi pasien retinopati hipertensi berdasarkan derajatnya dinilai oleh 2 orang ahli memperlihatkan bahwa derajat terbanyak pada ahli pertama adalah $\mathrm{KW}$ II = $58.9 \%$. Pun pada ahli ke dua, derajat terbanyak adalah KW $\mathrm{I}=56.8 \%$. Secara keseluruhan, prevalensi perubahan retina adalah $84.3 \%$ and $84.7 \%{ }^{23}$

Retinopati hipertensi kronik jarang menimbulkan kelainan penglihatan yang signifikan. Tata laksana dari penyebab utama bisa menghentikan progres perubahan retina, tapi penyempitan arteriol dan AV nicking tetap permanen. Untuk malignant hypertensive retinopathy, penurunan tekanan darah secara terkontrol bisa meminimalisir kerusakan target organ. Dalam kondisi darurat, yang terpenting adalah mencegah kerusakan akhir organ. 
Tekanan darah harus diturunkan dengan perlahan, hati-hati, dan terkontrol untuk mencegah kerusakan akhir organ. Jika terlalu kencang, bisa menyebabkan iskemia saraf optik, otak, dan organ vital lain. ${ }^{24}$

Grade retinopati hipertensi terbanyak adalah KW II, yaitu sebanyak 31 (46.2\%) orang pada pasien dengan TDS $\geq 160$ dan/atau TDD $\geq 100,26$ (38.8\%) pasien pada pasien yang menderita hipertensi $\geq 5$ tahun, dan $41(61.1 \%)$ pasien dengan umur $\geq 40$ tahun. Sesuai dengan kepustakaan, bahwa perubahan vaskular pada retina atau terjadinya retinopati hipertensi berkaitan dengan derajat keparahan hipertensi, onsetnya (kronik atau akut), durasi dari gejala, dan usia pasien. ${ }^{25}$ Adanya hubungan antara peningkatan tekanan darah dengan insiden retinopati hipertensi. ${ }^{15}$ Selain peningkatan tekanan darah, faktor lain yang berperan pada retinopati hipertensi adalah lamanya pasien menderita hipertensi. Penyempitan arteri retina dan AV nicking menjadi penanda hipertensi yang berlangsung kronis. Perubahan retina itu secara langsung berkaitan dengan peningkatan tekanan darah yang diukur 5-8 tahun sebelumnya. ${ }^{9}$ Faktor lain yang berhubungan dengan retinopati hipertensi adalah usia. Penelitian menunjukkan bahwa tandatanda retinopati hipertensi meningkat seiring bertambahnya usia dan peningkatan tekanan darah. ${ }^{19}$

\section{SIMPULAN}

Sebagian besar pasien retinopati hipertensi menderita hipertensi berjenis kelamin perempuan. Sebagian besar pasien retinopati hipertensi dengan Keith-Wagerner-Barker II. Sebagian besar pasien retinopati hipertensi dengan Keith-Wagerner-Barker II pada pasien dengan TDS $\geq 160$ dan/atau TDD $\geq 100$, yang menderita hipertensi $\geq 5$ tahun, dan dengan umur $\geq 40$ tahun

\section{DAFTAR PUSTAKA}

1. JNC 7. The Seventh report of the Joint National Committee on Prevention, Detection, Evaluation, and Treatment of high blood pressure. America: NIH Publication; 2003.

2. Kementrian Kesehatan Republik Indonesia. Panduan peringatan hari kesehatan sedunia
2013, 7 April 2013. Jakarta: Kementrian Kesehatan Republik Indonesia; 2013.

3. Kementrian Kesehatan Republik Indonesia. Laporan hasil riset kesehatan dasar (RISKESDAS) Indonesia tahun 2013. Jakarta: Badan Penelitian dan Pengembangan Kesehatan Departemen Kesehatan Republik Indonesia; 2013.

4. Dinas Kesehatan Kota Padang. Profil kesehatan tahun 2013. Padang: Dinas Kesehatan Kota Padang; 2013.

5. Sudoyo AW, Setiyohadi B, Alwi I, Simadribata M, Setiati S, editor (penyunting). Buku ajar ilmu penyakit dalam edisi VI. Jakarta: Interna Publishing. 2014.hlm.2267-70.

6. Grosso A, Veglio F, Porta M, Grinolo FM, Wong TY. Hypertensive retinopathy revisited: some answer, more questions. Br. J. Ophthalmol. 2005; 89:1646-54.

7. Wong TY, Mitchell $P$. The eye in hypertension. The Lancet. 2007;369 9559: 425-35.

8. American Academy of Ophthalmology. Retina and vitreous section 12. San Fransisco: American Academy of Ophthalmology; 2011.hlm.107-8.

9. Wong TY, Mclntosh R. Hypertensive retinophaty signs as risk indicators of cardiovascular morbidity and mortality. British Medical Bulletin. 2005; 73 and 74:57-70.

10. Wong TY, Mitchell P. Hypertensive retinopathy. New England Journal of Medicine. 2004;354: 2310-17.

11. Oladapo O, Salako L, Sadiq L, Shoyinka K, Adedapo K, Falase AO. 2012. Target-organ damage and cardiovascular complications in hypertensive Nigerian Yoruba adults: a crosssectional study. Journal of Africa. 2012; 23(7): 379-84.

12. Setyowati S. Faktor faktor yang berperan terhadap kejadian retinopati hipertensi pada pasien hipertensi esensial non diabetik (tesis). Semarang: Fakultas Kedokteran Universitas Diponegoro;2005.

13. Wong TY, Klein R, Klein BE, Tielsch JM, Hubbard L, Nieto FJ. Retinal microvascular abnormalities and their relationship with hypertension, 
cardiovascular disease, and mortality. Surv Ophthalmol. 2001. ;46(1):59-80.

14. Islam FMA, Klein BEK, Klein R, Wong TY, Cotch MF, Castro C, Sharrett AR, Shahar E. Retinal vascular caliber, cardiovascular risk factors, and inflammation: The Multi-Ethnic Study of Atherosclerosis (MESA). IOVS. 2006;47(6): 234150.

15. Besharati MR, Rastegar A, Shoja MR, Maybodi ME. Prevalence of retinopathy in hypertensive patients. Saudi Med J. 2006;27(II):1725-8.

16. Kabedi NN, Mwanza JC, Lepira FB, Kayembe TK, Kayembe DL. Hypertensive retinopathy and its association with cardiovascular, renal and cerebrovascular morbidity in Congolese patients. Cardivaskular Journal of Africa. 2014;25(5):22832.

17. Klein R, Klein BE, Moss SE. The relation of systemic hypertension to changes in the retinal vasculature: the Beaver Dam Eye Study. Trans Am Ophthalmol. 1997;95:329-50.

18. Sharrett AR, Hubbard LD, Cooper LS, Sorlie PD, Brothers RJ, Nieto FJ, Pinsky JL, Klein R. Retinal arteriolar diameters and elevated blood pressure: the Atherosclerosis Risk in Communities Study. American Journal of Epidemiology. 1999.;150(3):263-70.

19. Cheung CYL, Wong TY. "Hypertension" in Retina. Ryan SJ, Scharhat AP, Wilkinson CP, Hinton DR, Sadda SR, Hiederann P (Ed). Canada: Elsevier. 2012.hlm.1001-5.
20. Sedayu B. Karakteristik pasien hipertensi di bansal rawat inap SMF Penyakit Dalam RSUP dr. M. Djamil Padang tahun 2013 (skripsi). Padang: Fakultas Kedokteran Universitas Andalas; 2014.

21. Hamidi AA. Prevalensi hipertensi esensial pada pasien yang dirawat di bagian Penyakit Dalam RSUP dr. M. Djamil Padang tahun 2010 (skripsi). Padang: Fakultas Kedokteran Universitas Andalas; 2013.

22. Neto JAF, Palacio GL, Santos AN, Chaves PSS, Gomes GV, Cabral TS. Direct ophthalmoscopy versus detection of hypertensive retinopathy: $A$ comparative study. Arq Bras Cardiol. 2010;95(2): 215-22.

23. Cuspidi C, Meani S, Salerno M, Fusi V, Severgnini $B$, Valerio $C$, et al. Retinal microvascular changes andtarget organ damage in untreated essential hypertensives. J Hypertens. 2004;22(11):2095102.

24. Rogers $\mathrm{AH}$. Hypertensive retinopathy. Dalam: Yanoff, Duker ophthalmology. Goldstein $\mathrm{MH}$, Rosen ES, Duker JS, Rao NA, Augsburger JJ, Sadun AA, Schuman JS, Diamond GR, Dutton JJ, editor (penyunting). China: Elsevier. 514-7.

25. Kim SK, Mieler WF, Rubin MP, Jacobiec FA. Hypertension and its ocular manifestations. Dalam: Albert DM, Miller DT, Tazar D, editor (penyunting). Albert and Jacobiec's principles and practice of opthalmology. Philadelphia: Elsevier. 2008.hlm.4367-84. 